for this cytochrome (Biochim. Biophys. Acta, 234, 126; 1971). They have carefully analysed light minus dark difference spectra measured over the wavelength region of 500 to $600 \mathrm{~nm}$ on intact leaves and isolated chloroplasts at $77 \mathrm{~K}$. At this temperature the spectra obtained are due to electron transfer between donors and acceptors which are in very close proximity.

Boardman et al. have confirmed the observation of Knaff and Arnon (Proc. US Nat. Acad. Sci., 64, 715; 1969) that cyt $b_{559}$ is oxidized at $77 \mathrm{~K}$ by light primarily absorbed by $\mathrm{S} 2$ and have presented further evidence that this photooxidation only occurs when the primary electron acceptor of S2 (called $E$ by Boardman) is not reduced. Therefore it seems that cyt $b_{559}$ donates electrons to, rather than, as originally thought, accepting them from, E. If this is so, then it could mean that cyt $b_{559}$ functions as a carrier for cyclic electron flow.

In the same article it is convincingly shown that cyt $f$, the c-type cytochrome which is also found in chloroplasts, is not photo-oxidized at $77 \mathrm{~K}$. In the past it has been reported that this cytochrome is photo-oxidized by S1 light both at room and liquid nitrogen temperatures (B. Chance and W. D. Bonner, in Photosynthetic Mechanisms in Green Plants: Nat. Acad. Sci.-Nat. Res. Council Pub. No. 1145, 66 ; 1963). Because of this it had been concluded that not only did cyt $f$ lie on the principal electron transport pathway between the two photo-systems but that it was in intimate contact with the reaction centre chlorophyll of S1. The confusion whether or not cyt $f$ is photooxidized at low temperature apparently arose because of a misinterpretation of the bands which occur at $547 \mathrm{~nm}$ and $557 \mathrm{~nm}$ in the light minus dark difference spectra at $77 \mathrm{~K}$. It is now well established that the $557 \mathrm{~nm}$ absorbancy change is due entirely to the photooxidation of cyt $b_{559}$ and the $547 \mathrm{~nm}$ band has clearly been shown by Boardman's group not to correspond to the $548 \mathrm{~nm}$ band associated with cyt $f$ oxidation. In fact, the Canberra group have confirmed Arnon's proposal that the low temperature light induced spectral change at $547 \mathrm{~nm}$ is due to a primary photoreduction. The nature of the photoreduced compound is unknown but could be the primary electron acceptor of S2 (E).

The removal of cyt $b_{559}$ from the electron transport chain linking $\mathrm{S} 2$ and $S 1$ leaves an embarrassing gap in the well established " $Z$ " scheme. This can only mean that students of photosynthesis will have to accept yet another letter of the alphabet to signify a hypothetical intermediate which acts on the reducing side of $E$.
MAN-MADE LAKES

\section{Problems Defined}

from a Correspondent

A BROADLy based interdisciplinary symposium on the problems and environmental effects of man-made lakes was held at the University of Tennessee, Knoxville, Tennessee, from May 3 to 7, under the auspices of the Scientific Committee on Water Research (COWAR) and the International Council of Scientific Unions (ICSU).

It was immediately apparent that there is a need for a register of manmade lakes of the world. Dr R. Keller (University of Freiburg) suggested that such a register be compiled by one of the UNESCO organizations to complement the World Register of Dams. The latter publication gives engineering details of about 10,000 dams but provides few specifications concerning the dammed water bodies.

The importance of preimpoundment studies in relation to public health, population resettlement and other socio-economic factors was stressed by several contributors. Dr E. A. K. Kalitsi (Volta River Authority, Ghana) considered the Volta Lake as one of the major instruments for transforming the Ghanian economy. The formation of the lake had created new economic possibilities but it had not been possible to exploit fully the opportunities offered. Failure to complete land acquisition and land clearance before resettlement had led to a lowering rather than an increase in production. Similarly, failure to implement fully irrigation programmes, the development of lake fisheries, transport and tourism has given rise to unrealized expectations.

Dr A. W. A. Brown (World Health Organization) considered the public health problems created by man-made lakes. In tropical and subtropical manmade lakes, notably those in Africa, explosive outgrowths of water weeds after filling had led to a very significant increase in the incidence of diseases carried by insects, such as malaria and oncocerciasis, and by molluscs such as schistosomiasis. The need for containment of disease vectors and for adequate environmental sanitation was emphasized, and it was suggested that a centre should be set up to study these problems.

In the field of limnology Professor B. R. Allanson (Rhodes University) stressed the need for continued fundamental research by multidisciplinary teams. He considered that appreciation of eutrophication might well be hampered by the continuing tendency to work within too rigid a framework of parameters. $\mathrm{He}$ suggested that although estimation of the elements nitrogen and phosphorus should not be discontinued there should be more emphasis on measurements of carbon.

\title{
Specificity of Antibody Responses
}

Heterogeneity among mouse lymphocyte populations which are morphologically very similar is a source of sadness to the descriptive cytologist and a great joy to the experimental cellular immunologist. At least two sorts of cells, named $T$ and $B$ to indicate their derivation from thymus and bone marrow respectively, are widely recognized. Numerous studies in which the derivation of cells has been determined have established this point beyond question.

But, aside from these organizational findings, many other workers have shown that B cells produce antibody whereas $T$ cells act in a cooperative role in antibody production, being apparently incapable of antibody synthesis themselves. Thus the heterogeneity is related not only to cell surface antigenicity and derivation but also to a functional attribute. In next week's Nature New Biology, Basten et al. show that the specificity of antibody responses in which cooperation between $B$ and $T$ cells has occurred is apparently determined by both of the cellular constituents of the reacting mixture.

The method adopted was to incubate either T or B cells (thymocytes or cells from the spleens of thymectomized irradiated bone-marrow injected mice) with a protein which had previously been bound to ${ }^{125} \mathrm{I}$. The incubated cells were then transferred into irradiated mice which were challenged with the same protein (not iodinated) or a control antigen. The theory was that the "hot" antigen would bind to and destroy those cells which normally react to the protein. The results indicated that a specific reduction of twenty to thirty-fold in the numbers of antibody releasing cells, as adjudged by a plaque assay, was evident when either $\mathrm{T}$ or $\mathrm{B}$ cells were incubated with the hot antigen. From a further series of experiments it seems that the receptor on the thymocytes for the protein antigen is an immunoglobulin or is linked with an immunoglobulin on the cell surface.

For the connoisseur it should be noted that suicide experiments with $\mathbf{B}$ cells present in bone marrow inocula failed. Basten et al.'s suggestion that there may well be few mature B cells in mouse bone marrow, implying therefore that this tissue is not a particularly useful source of B cells in cooperation experiments, may not be received kindly. 